\title{
Extending hospitality to customers with epilepsy
}

\section{Alison McIntosh}

Dr Alison McIntosh is a Professor of Hospitality \& Tourism at AUT. Her research focuses on issues of social justice and advocacy through tourism and hospitality in the pursuit of social change.

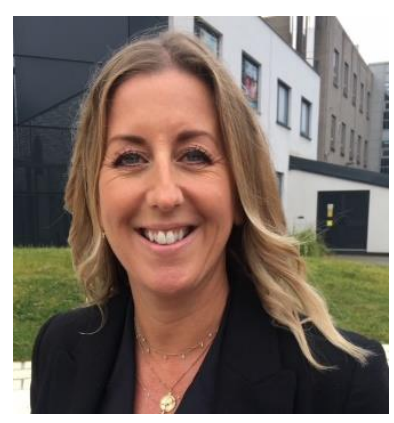

According to the World Health Organization, ${ }^{1}$ around 50 million people worldwide live with the invisible disability epilepsy. Research has found that the neurological condition is generally shown to reduce an individual's quality of life because it impacts on personal sense of control and can limit positive life experiences. ${ }^{2}$ However, little remains known about how an individual's experience of hospitality may be affected by the condition. This article reports on the findings of a recent study that aimed to explore the lived experiences of tourism and hospitality for people with epilepsy. ${ }^{3}$ The phenomenological indepth study concluded that, for the most part, hospitality customers with epilepsy were unaffected by their condition. Despite this finding, the study revealed important implications for the hospitality industry in terms of the need to provide greater support and accommodation to customers with epilepsy.

Although most of the study's respondents were found to have controlled their seizures through medication, they reported needing to follow an 'epilepsy plan' in the event that they have a seizure when out in public based on their known triggers. To further ensure their safety, respondents reported that they only travel if accompanied by a support companion, and/or a service animal. The physical accessibility of hospitality establishments was also claimed to be important, notably in relation to wheelchair access (if required) and physical and private spaces in case of a seizure. However, one of the most significant findings was the individual's preference for non-disclosure of their condition. As one respondent explained,

"If we go into a restaurant for a meal, unless [name] had a seizure right in the middle of the meal, we probably wouldn't say anything."

Despite regulations that prohibit the discrimination of people with disabilities, the lack of disclosure was attributed to individuals' fear and perceived stigma in relation to the reactions of other people. Misunderstandings of the condition have been widely noted. $\mathrm{ct}$ Respondents commented that sometimes hospitality staff have been known to confuse behaviours associated with an epileptic seizure with a mental health or some other stigmatising condition. For example, some people may be quite alert during a seizure but appear 'odd' in 
terms of their behaviour; they may start tapping their feet, or decide they can smell something, or feel disconnected. Some people may appear 'drunk and disorderly' in their seizure pattern. As such, there is a need for greater awareness, beyond basic first aid training, of the forty different epileptic seizure types and what they might look like. This may start with gaining information about the common triggers for epileptic seizures, and how to respond, from a tailored session with a local epilepsy advocacy agency, or their online training resources.

There is a need for hospitality providers to consider access, support and accommodation for people with epilepsy. The result of lack of awareness is that people with epilepsy remain restricted in their ability to enjoy life and stigmatised by their condition. An epilepsy advisor in the study explained,

"It is about giving them the confidence; it is that you will look after them, you will make them secure. It is not about disabling them; it is about enabling them to cope and that's where you go through in understanding their seizure triggers and their seizures so that they understand how to cope for themselves."

The study respondents' advice to the hospitality industry was to become aware, informed and 'just ask', rather than reacting with fear and ignorance. Hospitality, to them, was related to extending a welcome to people with epilepsy into the café, restaurant, motel or hotel and asking their needs, so that if a seizure happens, hospitality workers know how to help. In the words of one respondent, "You're made welcome, and whatever happens, you are still welcome."

\section{Corresponding author}

Alison McIntosh can be contacted at: alison.mcintosh@aut.ac.nz.

\section{References}

(1) World Health Organization (2019, June). Epilepsy. Key Facts. https://www.who.int/newsroom/fact-sheets/detail/epilepsy.

(2) Bishop, M., Allen, A. The impact of epilepsy on quality of life: A qualitative analysis. Epilepsy \& Behavior, 2003, 4, 226-233. https://doi.org/10.1016/j.annals.2019.102856

(3) McIntosh, A. J. (2020). The hidden side of travel: Epilepsy and tourism. Annals of Tourism Research, 2020, 81, 102856.

(4) Jacoby, A. Stigma, epilepsy and quality of life. Epilepsy \& Behavior, 2002, 3(Suppl.), S10S20. https://doi.org/10.1016/s1525-5050(02)00545-0. 